Максим Гаврилков

DOI: $10.31168 / 91674-576-4.06$

Институт славяноведения РАН, Россия

reven1995@gmail.com

- Новое о цитатном пространстве «Стязания о извђстном иночьскомь жительствЊ...» Максима Грека

Полемическое сочинение Максима Грека рассматривается на двух уровнях: текстологическом и функциональном. Первый представлен новой, уточненной и наиболее полной атрибуцией библейских и святоотеческих цитат и их тематическим членением. Второй уровень представлен композиционной перестройкой цитатного пространства, которое формирует «Лествицу спасения» и тем самым реализует основной императив конфессиональной культуры.

Ключевые слова: Максим Грек, «Лествица спасения», циитатное пространство, функцииональность, атрибуичя

Несмотря на разметку цитатного пространства «Стязания о извђстном иночьскомъ жительствђ, лица же стязующихся Филоктимонъ да Актимонъ, сирьчь любостяжателныи да нестяжателныи», осуществленную при его критическом издании 2014 г. под редакцией Н. В. Синицыной [Грек 2014: 219-230], часть цитат осталась неатрибутированной, некоторые отмеченные цитаты содержали ошибки и неточности атрибуции как в протяженности цитируемого текста, так и в его источнике. В издании была представлена двухуровневая маркировка цитат: во-первых, указание библейского источника на полях напротив строки, содержащей последнее слово цитаты (или строкой ниже в случае расположения нескольких цитат на одной строке), и, во-вторых, расстановка знаков цитирования - кавычек. 
Проведенная сверка «Стязания...», и в особенности уже обозначенных издателями цитат, с библейскими текстами позволила уточнить атрибуцию и выявить новые цитаты, несущие принципиальное значения для интерпретации текста.

Расхождения, уточнения и атрибуция еще не выделенных цитат здесь приводится в сопоставительном аспекте. Указывается страница в издании 2014 г. [См.: Таблица 1].

Таблица 1

Новое в атрибуции цитатного пространства «Стязания...»

\begin{tabular}{|c|c|}
\hline $\begin{array}{l}\text { [Преп. Максим Грек. } \\
\text { Т. 2, С. 219-230] }\end{array}$ & Новая атрибуция $\left(M \Gamma^{1}\right)$ \\
\hline Нет атрибуции & 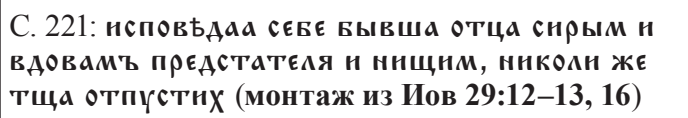 \\
\hline Нет атрибуции & С. 221: днесь сПасенHе дому сему (ЛК 19:9) \\
\hline Нет атрибуции & $\begin{array}{l}\text { С. 222: ВБра во кромь влаГыХ АБ } \\
\text { єсть (Иак 2:17, 26.) }\end{array}$ \\
\hline Нет атрибуции & $\begin{array}{l}\text { С. 222: ЕСТЬ ГААВИЗНА ВСБМ БОЖЕСТВЕНЫМ } \\
\text { ЗАПОВБАЕМЪ ЕГО н СЪҢЗЪ СЪВРЪШЕНЬСТТА } \\
\text { (КОЛ 3:14) }\end{array}$ \\
\hline Нет атрибуции & 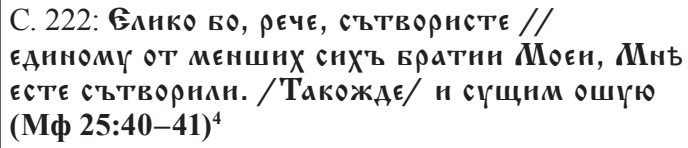 \\
\hline
\end{tabular}

1. Максим Гаврилков.

2. Следует предположить случайный недосмотр издателей, поскольку данное место уже было выделено в предыдущих изданиях и переводах текста [Сочинения 1860: 96; Сочинения 1910: 60].

3. Благых - инородная вставка Максима Грека. Отсутствует в библейском источнике. Нуждается в атрибуции (возможно, влияние толкования Иоанна Златоуста на Кол. 3:14).

4. В издании 1860 г. дана неполная атрибуция: Мф 25:40. 


\begin{tabular}{|c|c|c|}
\hline & 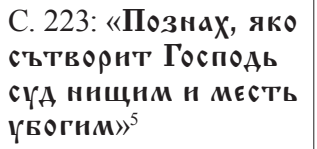 & $\begin{array}{l}\text { С. 223: ПознаХ, яко сътворнт Господь сУА } \\
\text { нищнМ и Месть үБогим (Пс 139:13) }\end{array}$ \\
\hline 32 & $\begin{array}{l}\text { С. 223: «ОАЕБЕАЬ БО } \\
\text { СЕРАЦЕ НАШЕ», ЯКОЖЕ } \\
\text { ИСАНА РЕЧЕ О АРЕВ- } \\
\text { нЕМ ЖЕСТОКОВЫМ } \\
\text { ИНЗРАНАН, «Н УШН- } \\
\text { МА ТЯЖКО САЫШНМ» } \\
\text { (ИС 6:12) }\end{array}$ & $\begin{array}{l}\text { С. 223: ОАЕБЕАЬ БО СЕРАЦЕ, ЯКОЖЕ ИСАНА РЕЧЕ } \\
\text { О АРЕВНЕМ ЖЕСТОКОВЫМ ИНЗРАНАН, НАШЕ } \\
\text { Н УШНМА ТЯЖКО САЫШНМ (ИС 6:10) }\end{array}$ \\
\hline & Нет атрибуции & С. 224: вьру, снрьчь, сүА н мниость (Мф 23:23) \\
\hline & Нет атрибуции & С. 224: снХ ПОАОБАШе ТВОРНТН (Мф 23:23) \\
\hline & Нет атрибуции & $\begin{array}{l}\text { С. 224: н онБХ не остАвнтН } \\
\text { (Мф 23:23) }\end{array}$ \\
\hline & Нет атрибуции & $\begin{array}{l}\text { С. 224: Превзыти правАУ Фарн//ссьнску (Мф } \\
\text { 5:20) }\end{array}$ \\
\hline & Нет атрибуции & $\begin{array}{l}\text { С. 224: не внНАЕТЕ вЪ ЦАрСТВо НеБесное (Мф } \\
\text { 5:20) }\end{array}$ \\
\hline & Нет атрибуции & $\begin{array}{l}\text { С. 225: ВетХая Бо мнмондоша вся Быша нова } \\
\text { (II Кор 5:17) }\end{array}$ \\
\hline & Нет атрибуции & 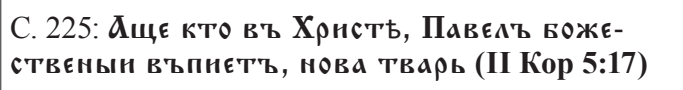 \\
\hline & Нет атрибуции & $\begin{array}{l}\text { С. 225: ОТАОЖНМ ОТ СЕБЕ ВСЯ АБАА ВЕТХАГО } \\
\text { чЕАОВБКА, ЯЖЕ СУТЬ БАУА ВСЯКЪ, НЕПРАВАА, } \\
\text { АНХОНМАННЕ, ХЫЩЕННЕ, ТАТБА, ПНАНЬСТВО, } \\
\text { БЕЗЧНННЕ ВСЯКО Н БЕЗСТУАСТВО (МОНТАЖ ИЗ } \\
\text { РАЗНЫХ МЕСТ КОЛ 3) }\end{array}$ \\
\hline & 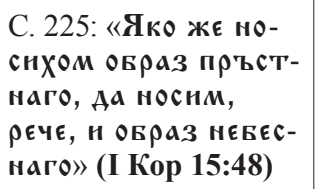 & 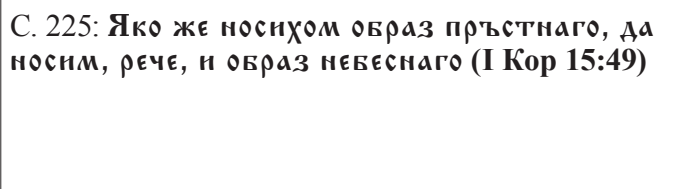 \\
\hline
\end{tabular}

5. Маркирован курсивом в дореволюционных изданиях, кавычками в издании 2014 г., но атрибуция отсутствует. 


\begin{tabular}{|c|c|}
\hline Нет атрибуции & 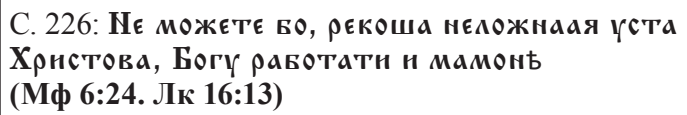 \\
\hline Нет атрибуции & $\begin{array}{l}\text { С. } 226: \text { АЮБОВНЮ СЪВРЪШЕНОЮ, ЯЖЕ ЕСТЬ } \\
\text { СЪУЗЪ СЪВРЪШЕНЬСТВА Н ВСЕГО ЗАКОНА НСПОА- } \\
\text { НЕННЕ (КОЛ } 3: 14 \text { ) }\end{array}$ \\
\hline $\begin{array}{l}\text { С. } 227: \text { ПрестуП- } \\
\text { ннкы възмнбХ вся } \\
\text { грБшныа земки» } \\
\text { (Пс 118:119) }\end{array}$ & 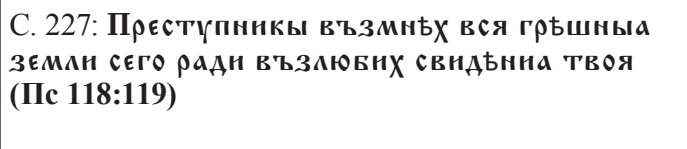 \\
\hline Нет атрибуции & $\begin{array}{l}\text { С. 227: НЕСЫТНО СЕРАЦЕ ПРЕГРЪААГО ОЧЕСЕ } \\
\text { (ПС 100:5) }\end{array}$ \\
\hline Нет атрибуции & 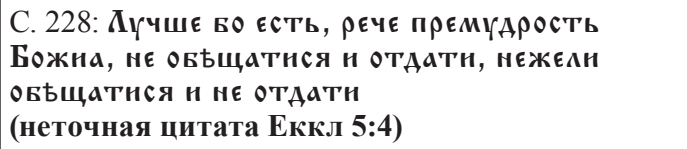 \\
\hline $\begin{array}{l}\text { С. 229: «НИКТО ЖЕ, } \\
\text { РЕЧЕ, ВЪННЬСТВУА } \\
\text { СЪПАЕТАЕТСЯ ЖНТЕ- } \\
\text { НСКЫМН КУПАЯМН» } \\
\text { (II ТИМ 2:4) }\end{array}$ & $\begin{array}{l}\text { С. 229: НИКТО ЖЕ, РЕЧЕ, ВЪННЬСТВУА } \\
\text { СЪПИЕТАЕТСЯ ЖНТЕНСКЫМН КУПАЯМН, АА } \\
\text { ПРНЧНТАВШЕМУ ЕГО ВЪ ВОННБХ УГОАНТЪ } \\
\text { (ІІ ТИМ 2:4) }\end{array}$ \\
\hline Нет атрибуции & 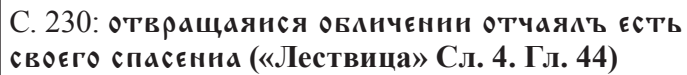 \\
\hline
\end{tabular}

Количественно преобладают цитирования самых читаемых в процессе литургии текстов: Псалтырь 23 цитаты; Мф - 18; Лк - 8; Ин, Кол — 4; I Кор, II Кор - 3; Ис, Иак, Евр - 2; Иов, Еккл, I Ин, Рим, I Тим, II Тим, «Лествица» Иоанна Синайского - 1 .

Выделяется присутствие цитаты из небиблейского текста, из «Лествицы» Иоанна Синайского. Это единственная цитата, относящаяся не к Священному Писанию, а аскетическому разделу патристики. Обращение к определенному святоотеческому прецедентному авторитетному тексту задано тематическим императивом. Именно «Лествица» Иоанна Синайского задает идеал 
монашеской жизни, подробно описывает необходимые обеты для соблюдения и иллюстрируется историями жизни раннехристианских монахов.

Ввиду явно обозначенной цитаты из «Лествицы», являющейся ключевой для понимания цитатного пространства можно поставить вопрос о наличии имплицитных лествичных цитат в тексте.

Членение цитат по тематическому принципу обусловливает выделение следующих тем:

- Богатства, включающая «подтемы»:

- благотворительности (раздача богатства, отказ от имущества)

$\circ$ ростовщичества (лихоимства),

○ стяжания,

○ нищеты;

- Праведности-неправедности:

॰ любви,

○ мирского,

○ правды фарисейской,

○ непонимания;

- Спасения;

- Совершенства;

- Царства небесного;

- Обличения;

- Покаяния.

В Таблице 2 цитатные атрибуции распределены по темам, тематические столбцы расположены в определенном порядке, отражен принцип последовательности цитат в тексте. Знак « » используется для избежания дублирования референции, когда цитата содержит несколько тем. 


\section{Таблица 6}

Тематическое распределение цитатного пространства

\begin{tabular}{|c|c|c|c|c|c|c|}
\hline 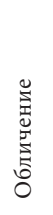 & 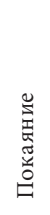 & 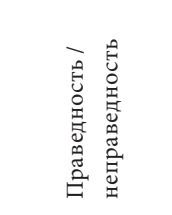 & 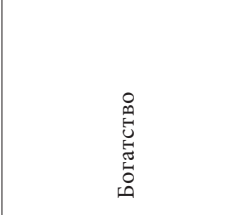 & 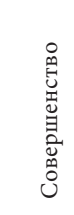 & 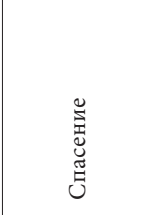 & 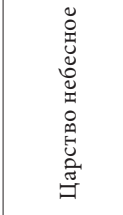 \\
\hline & & $\begin{array}{l}\text { Мф 3:12 } \\
\text { Пс 145:9 } \\
\text { Пс 93:6 } \\
\text { Мф 25:41 } \\
\text { Иак 2:17, } 26 \\
\text { Ин 14:21, } 24 \\
\text { Ин 15:14 } \\
\text { І Ин 2:4 } \\
\text { Мф 25:40 } \\
\text { Пс 11:6 } \\
\text { Пс 139:13 } \\
\text { Пс 9:19 } \\
\text { Иак 2:13 } \\
\text { Ис 6:10 } \\
\text { Мф 23:23 } \\
\text { Мф 5:20 } \\
\text { ІІ Кор 5:17 } \\
\text { Мф 5:20 }\end{array}$ & $\begin{array}{l}\text { Мф 19:29 } \\
\text { (Лк 18:29, 30) } \\
\text { Лк 9:62 } \\
\text { Пс 81:3 } \\
\text { Кол 3:14 } \\
\text { Мф 23:23 } \\
\text { Пс 111:9 } \\
\text { Мф 6:24 } \\
\text { (Лк 16:13) } \\
\text { Мф 13:22 } \\
\text { Пс 61:11 } \\
\text { І Тим 6:10 }\end{array}$ & $\begin{array}{l}\text { Мф } \\
5: 48\end{array}$ & $\begin{array}{l}\text { Лк 9:56 } \\
\text { Лк 19:9 } \\
\text { Мф 20:28 }\end{array}$ & $\begin{array}{l}\sim \\
\text { I Kop } \\
\text { 15:50 } \\
\text { Mф 5:20 }\end{array}$ \\
\hline
\end{tabular}




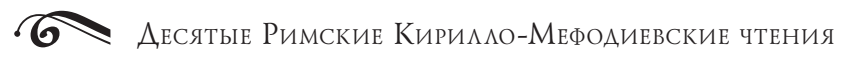

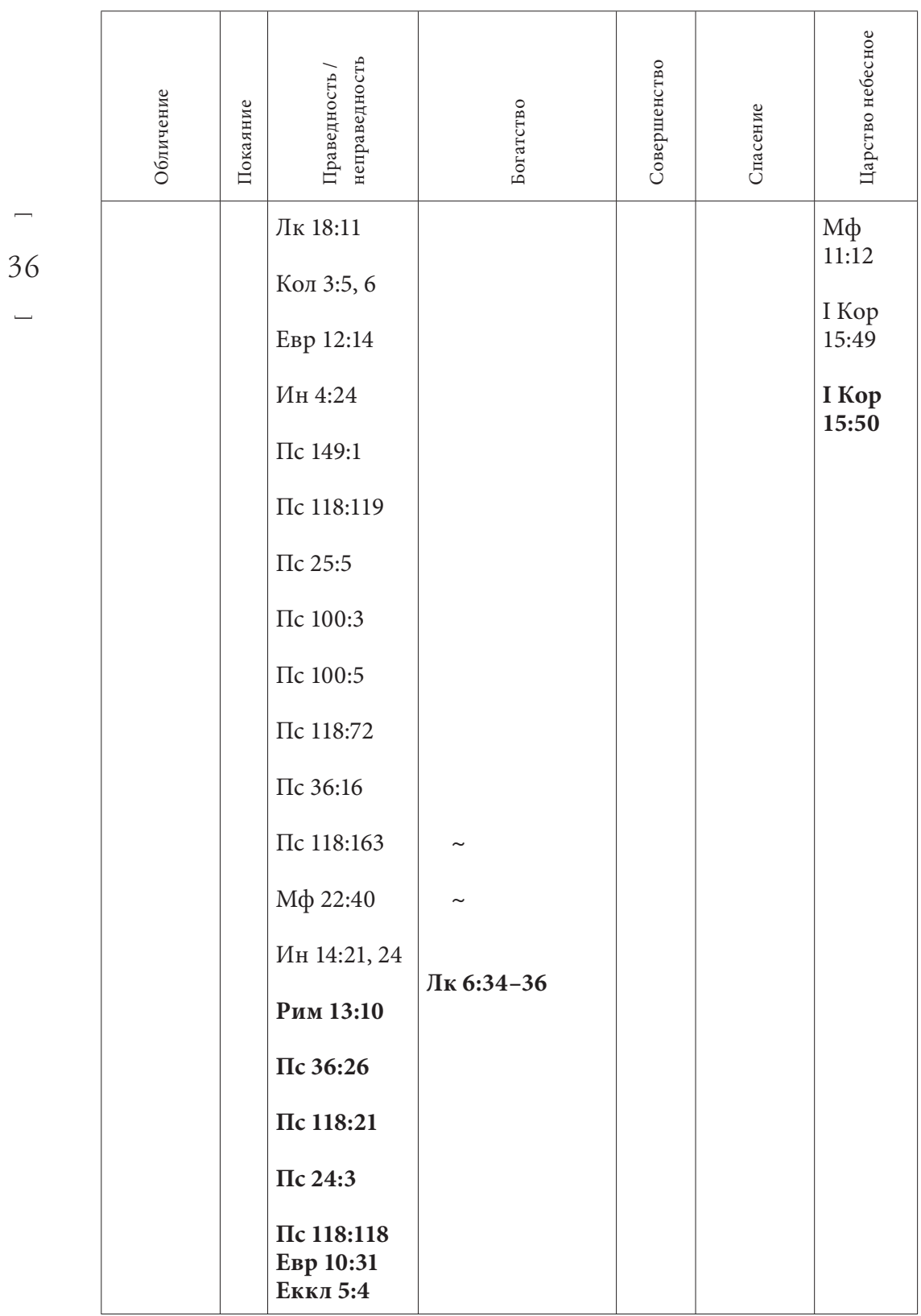




\begin{tabular}{|c|c|c|c|c|c|c|}
\hline 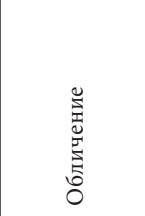 & 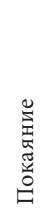 & 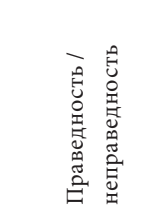 & 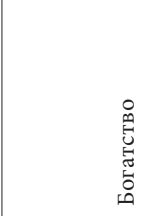 & 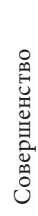 & 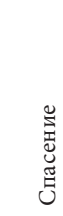 & 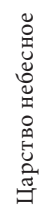 \\
\hline $\begin{array}{l}\text { Лествица } \\
\text { Сл. } 4 . \\
\text { Гл. } 44\end{array}$ & $\sim$ & $\begin{array}{l}\text { Пс 75:12 } \\
\text { Пс 5:7 } \\
\text { ІІ Тим 2:4 } \\
\text { Лк 9:23 } \\
\text { (Мф 16:24) } \\
\text { Ис 1:19 }\end{array}$ & $\begin{array}{c}\sim \\
\text { Mф 19:21 }\end{array}$ & $\sim$ & $\begin{array}{l}\sim \\
\sim\end{array}$ & \\
\hline
\end{tabular}

Важная словесная формула выносится в название другого соположенного со «Стязанием» сочинения Максима Грека: «сковеса Аушєполезна зБло вннмающнм нхъ». Такая словесная формула ставит задачу перед читателем быть особо внимательным и прилагать усилия к пониманию, иначе все окажется тщетно. Практически это означает необходимость прочтения цитатного пространства на двух уровнях и необходимость произвести манипуляции над текстом.

Императивность конфессиональной культуры должна задавать императивность порождаемых в ее рамках текстов: идея спасения должна быть императивной для книжности. Идея спасения тесно сопряжена с идеей царства небесного. Действительно, в «Стязании» императивом является идея спасения. Выявить это позволяет цитата из «Лествицы» Иоанна Синайского, завершающая сочинение перед формульным окончанием «ЗАравьствците О Господђ!»: «отвращаянся ОБАНЧЕННН ОТЧАЯАЪ ЕСТЬ СВОЕГО СПАСЕННА". 
«Лествица», входя в комплекс аскетических текстов, является руководством к совершенствованию, адресованном монахам. Именно в самом характере «Лествицы» открывается ключ к пониманию функциональной нагруженности цитат в сочинении Максима Грека: он предлагает путь совершенствования, являющий путь к спасению. Здесь актуализируется влияние Савонаролы, оказанное на Максима Грека. Центральная тема проповедей Савонаролы - покаяние. Только так можно стяжать милость божию и благодать.

Лествичная цитата задает тему обличения неправедной жизни. Обличение рассматривается в перспективе спасения, выводящего на достижение царства небесного. Так, расположенная в сильной позиции цитата явно усиливает тематический ключ, находящийся в третей и четвертой репликах текста. Более того, она выводит на более глубокое понимание используемого Максимом Греком цитатного пространства, воплощающего идею совершенствования. Цитата прочерчивает основанный на конкретных действиях духовный путь, по которому должен следовать праведный инок: от обличения до спасения.

Цитатное пространство имеет иерархический, «лествичный», характер, заключающийся в восхождении по тематически обусловленным «ступеням». Такая «цитатная лествица» непосредственно призвана реализовать императив конфессиональной культуры и интенцию книжника. Последнее представляется верным ввиду плачевной, с конфессиональной точки зрения, ситуации, в которой оказываются оппоненты авторской позиции: любостяжательные не достигают царствия небесного. Тематическая иерархия «ступеней» «цитатной лествицы» представляется организованной следующим образом: Царство небесное $\leftarrow$ Спасение $\leftarrow$ Совершенство $\leftarrow$ Нестяжательство (тема богатства) $\leftarrow$ Праведность $\leftarrow$ Покаяние $\leftarrow$ Обличение. 
Так, нелинейно прочитанное цитатное пространство выстраивает следующий путь праведного инока, путь исправления, на который должны встать стяжатели: обличение в грехах, признание обличения, отказ от богатства, его полная раздача нуждающимся, достижение совершенства и спасение.

\section{Литература}

Грек 2014 - Преподобный Максим Грек. Сочинения. Т. 2 / Отв. ред. Н. В. Синицына. М.: Рукописные памятники Древней Руси, 2014. 432 с.

Сочинения 1860 - Сочинения преподобного Максима Грека: в 3 ч. Казань, 1860. Ч. 2. 460 с.

Сочинения 1910 - Сочинения преподобного Максима Грека в русском переводе. Свято-Троицкая Сергиева лавра, 1910. Ч. $1.291 \mathrm{c}$.

\section{Maxim Gavrilkov}

Institute of Slavic Studies of the Russian Academy of Sciences, Russia reven1995@gmail.com

\section{Quotations in Maximus the Greek's}

\section{"Dispute on the Avowed Monastic Life" Revisited}

The paper approaches Maximus the Greek's polemical work both from the text-critical and functional perspectives. The text-critical case study reveals a new, refined and most complete attribution of biblical and patristic quotations and their thematic division. Restructuring quotations so that they form the "Salvation Ladder" demonstrates presence of the main imperative of Christian culture in the text.

Keywords: Maximus the Greek, Salvation Ladder, quotation, functional approach, attribution 